\title{
Der Investiturstreit - Neuere Perspektiven der Forschung
}

\author{
Zey, Claudia
}

Posted at the Zurich Open Repository and Archive, University of Zurich

ZORA URL: https://doi.org/10.5167/uzh-188610

Book Section

Published Version

Originally published at:

Zey, Claudia (2020). Der Investiturstreit - Neuere Perspektiven der Forschung. In: Kohl, Thomas. Konflikt und Wandel um 1100 : Europa im Zeitalter von Feudalgesellschaft und Investiturstreit. Berlin: De Gruyter, 13-31. 


\section{Der Investiturstreit - Neuere Perspektiven der Forschung}

Erdbeben, Erneuerung, Konflikt, Revolution, Streit, Umbruch, Umwälzung, Wandel und Wende sind in alphabetischer Reihenfolge die gängigen Epitheta, wenn vom Investiturstreit im Allgemeinen und Teilaspekten des Reformzeitalters im Besonderen die Rede ist. Nicht selten findet man diese Begriffe auch in Kombination miteinander, wie etwa beim Begleitband zur Canossa-Ausstellung 2006 in Paderborn. Der Titel „Vom Umbruch zur Erneuerung“ ist mit einem Fragezeichen versehen ${ }^{1}$, was ebenfalls im Trend der letzten Jahre liegt. „Investiturstreit oder gregorianische Reform?“ fragten etwa Wolfgang Hasberg und Hermann-Josef Scheidgen in ihrem 2012 herausgegebenen Band „Canossa - Aspekte einer Wende“2. Die Frage nach „Libertas ecclesiae oder den Anfängen der Säkularisierung im Investiturstreit?“ stellte Gerd Althoff in einem gleichfalls 2012 erschienenen Sammelband, der unter dem Titel „Umstrittene Säkularisierung. Soziologische und historische Analysen zur Differenzierung von Religion und Politik“ mit vier Aufsätzen den Investiturstreit zum mittelalterlichen Schwerpunktthema macht und zu den großen Deutungsansätzen vergangener Jahrzehnte zurückführt $^{3}$. Die eingeschränkte Verwendung des Terminus „Investiturstreit“ durch das Hinzufügen von „der sogenannte“ (Investiturstreit) ist zwar nur noch selten anzutreffen $^{4}$, die dahinter stehenden Zweifel aber, was eigentlich der Kern dieses Kon-

1 Jörg Jarnut / Matthias Wemhoff (Hrsg.), Vom Umbruch zur Erneuerung? Das 11. und beginnende 12. Jahrhundert. Positionen der Forschung. Historischer Begleitband zur Ausstellung „Canossa 1077, Erschütterung der Welt. Geschichte, Kunst und Kultur am Anfang der Romanik.“ (MittelalterStudien 13) München 2006. Der Beitrag bezieht sich im Wesentlichen auf die Forschungssituation 2014. Jüngere Publikationen konnten ergänzt, aber nicht ausführlich besprochen werden.

2 Wolfgang Hasberg / Hermann-Josef Scheidgen, Investiturstreit oder Gregorianische Reform?, in: dies. (Hrsg.), Canossa. Aspekte einer Wende. Regensburg 2012, 39-55.

3 Gerd Althoff, Libertas ecclesiae oder die Anfänge der Säkularisierung im Investiturstreit?, in: Karl Gabriel / Christel Gärtner / Detlef Pollack (Hrsg.), Umstrittene Säkularisierung. Soziologische und historische Analysen zur Differenzierung von Religion und Politik. Berlin 2012, 78-100. Weitere Beiträge zum Investiturstreit in diesem Band: Hartmann Tyrell, Investiturstreit und gesellschaftliche Differenzierung. Überlegungen aus soziologischer Sicht, 39-77; Wilfried Hartmann, Gregor VII. und die Könige. Auf dem Weg zur Hierokratie?, 101-133; Sita Steckel, Säkularisierung, Desakralisierung und Resakralisierung. Transformationen hoch- und spätmittelalterlichen gelehrten Wissens als Ausdifferenzierung von Religion und Politik, 134-175 sowie der Kommentar von Otto Gerhard Oexle, 176-187. Die von Tyrell aus soziologischer Sicht aufgeworfene Frage, ob der Investiturstreit am Anfang der Säkularisierungsgeschichte stehe, wurde von Althoff und Hartmann mit verschiedenen quellenbasierten Argumenten verneint. Diese Auseinandersetzung kann als beispielhaft für Chancen und Grenzen des interdisziplinären Diskurses angesehen werden.

4 Vgl. ohne Anspruch auf Vollständigkeit: Claudia Zey, Der sogenannte Investiturstreit, in: Stefan Weinfurter / Frank Martin Siefarth (Hrsg.), Macht und Ordnungsvorstellungen im hohen Mittelalter. Werkstattberichte. (Münchner Kontaktstudium Geschichte 1) Neuried 1998, 89-105; Florian Hartmann, 
fliktes war, in welchem Verhältnis kirchenpolitische Fragen im engeren Sinne und machtpolitische Fragen im weiteren Sinne zueinander stehen, und vor allem, wie sich dieser Konflikt auf die soziale Ordnung des hochmittelalterlichen Europa auswirkte, ist genauso aktuell wie schon vor Jahrzehnten und deswegen immer wieder Anlass, die Verhältnisse im ausgehenden 11. und beginnenden 12. Jahrhundert in den Blick zu nehmen. Dieser Sammelband, entstanden aus einer Tagung zu „Konflikt und Wandel um 1100. Europa im Zeitalter von mutation féodale und Investiturstreit“ im Rahmen eines SFBs zu „Bedrohten Ordnungen“ legt davon beredt Zeugnis ab.

Mir wurde die Rolle zugedacht, neuere Perspektiven der Forschung zum Investiturstreit darzulegen und dabei vor allem das nordalpine Reich stärker in Augenschein zu nehmen. Eine, wie es zunächst scheint, eindeutige Aufgabe, zumal das Narrativ vom epochalen Konflikt zwischen regnum/imperium und sacerdotium nach wie vor die Einschätzung von Umbruch und Wendecharakter dieser Zeit bestimmt ${ }^{5}$. Auf der anderen Seite lösen sich neuere Ansätze schon seit Längerem von der Dichotomie Kaiser-Papst und beziehen gesamteuropäische Entwicklungen stärker mit ein ${ }^{6}$. Auch der

Zur Kunst des Schreibens im Investiturstreit, in: Gunther Gebhard / Oliver Geisler / Steffen Schröter (Hrsg.), StreitKulturen. Polemische und antagonistische Konstellationen in Geschichte und Gegenwart. Bielefeld 2008, 35-55, hier 35: „Der epochale Konflikt der universalen Gewalten, der nur unzureichend mit dem Etikett ,Investiturstreit“ versehen wurde (...)“; Claudius Sieber-Lehmann, Um 1079. Warum es für das Verhältnis von Papst und Kaiser kein erfolgreiches Denkmodell gab, in: Bernhard Jussen (Hrsg.), Die Macht des Königs. Herrschaft in Europa vom Frühmittelalter bis in die Neuzeit. München 2005, $150-164$, hier 150 .

5 Vgl. etwa die in Anm. 1, 2 und 4 genannten Arbeiten. Viele weitere Beiträge könnten hier genannt werden; exemplarisch Tilman Struve, Die Wende des 11. Jahrhunderts. Symptome eines Epochenwandels im Spiegel der Geschichtsschreibung, in: HJB 112 (1992), 324-365; Cinzio Violante / Johannes Fried (Hrsg.), Il secolo XI. Una svolta? (Annali dell' Istituto storico italo-germanico 35) Bologna 1993; Rudolf Schieffer, Motu proprio. Über die papstgeschichtliche Wende im 11. Jahrhundert, in: HJB 122 (2002), 27-41; Jochen Johrendt, Papstgeschichtliche Wende und produktive Zerstörung. Päpstliche Briefe im Zeitalter des Investiturstreits, in: Florian Hartmann (Hrsg.), Brief und Kommunikation im Wandel. Medien, Autoren und Kontexte in den Debatten des Investiturstreits. (Papsttum im mittelalterlichen Europa 5) Köln / Weimar / Wien 2016, 103-128. Zu den klassischen Deutungen des Investiturstreits vgl. Rudolf Schieffer, Deutungen des Investiturstreits, in: ebd., 23-41.

6 Vgl. Rudolf Schieffer, Gregor VII. und die Könige Europas, in: Studi Gregoriani 13 (1989), 189-211; Robert I. Moore, The First European Revolution, c. 970-1215. (The Making of Europe) Malden 2000; Rudolf Schieffer, Der Investiturstreit im Bilde der Zeit nach 1122, in: Klaus Herbers (Hrsg.), Europa an der Wende vom 11. zum 12. Jahrhundert. Beiträge zu Ehren von Werner Goez. Stuttgart 2001, 248-260; Timothy Reuter, Nur im Westen was Neues? Das Werden prämoderner Staatsformen im europäischen Hochmittelalter, in: Joachim Ehlers (Hrsg.), Deutschland und der Westen Europas im Mittelalter. (VuF 56) Stuttgart 2002, 327-351; Kathleen G. Cushing, Reform and Papacy in the Eleventh Century. Spirituality and Social Change. (Manchester Medieval Studies.) Manchester 2005; Maureen C. Miller, Power and the Holy in the Age of the Investiture Conflict. A Brief History with Documents. (The Bedford Series in History and Culture) New York 2005; Nicolangelo D’Acunto, L'età dell'obbedienza. Papato, impero e poteri locali nel secolo XI. (Nuovo Medioevo 75) Neapel 2007; Bernd Schneidmüller / Stefan Weinfurter (Hrsg.), Salisches Kaisertum und neues Europa. Die Zeit Heinrichs IV. und Heinrichs V. Darmstadt 2007; Maureen C. Miller, The Crisis in the Investiture Crisis Narrative, in: History Compass 7 (2009), 1570 1580; Megan McLaughlin, Sex, Gender and Episcopal Authority in an Age of Reform. 1000-1122. 
Vergleich zwischen einzelnen Reichen verbunden mit der Frage nach der Wirkmacht der reform- oder papstgeschichtlichen Wende hat $\mathrm{zu}$ einer Bereicherung des Forschungsspektrums geführt. Ludger Körntgen mahnte in einem 2013 erschienenen Aufsatzband zu Religion und Politik in Deutschland und Großbritannien an, Investiturstreit, Canossagang und Wormser Konkordat aus der Meistererzählung von der Säkularisierung als einer besonderen Errungenschaft Europas zu lösen und nicht vorschnell aus teleologischer Perspektive eine epochentrennende Wirkung des Konflikts $\mathrm{zu}$ postulieren, sondern das vielfältige und durchaus widersprüchliche Verhältnis von Religion und Politik vor und nach dem Streit zu beachten ${ }^{7}$. Zum selben Band steuerte Stuart Airlie einen Blick aus der Ferne bei („A View from Afar“), indem er Religion und Politik im Investiturstreit aus englischer Perspektive betrachtete, die Forschungstraditionen in Deutschland und England miteinander verglich und $\mathrm{zu}$ neueren Forschungsansätzen im anglo-amerikanischen Raum Stellung bezog ${ }^{8}$.

Die geographische Fokussierung auf das nordalpine Reich darf also als eine Orientierungshilfe für die Darlegung neuerer Forschungstendenzen im europäischen Kontext angesehen werden. Eine Einschränkung muss sich eher auf die Auswahl einzelner Schwerpunkte beziehen. Es ist kaum noch möglich, alle Facetten der Forschungen zum Investiturstreit wahrzunehmen, geschweige denn, sie im Rahmen eines Beitrags darzustellen. Überdies ist eine gewisse Subjektivität im Zugriff auf die Deutungsschemata unumgänglich und meines Erachtens auch wünschenswert, wenn es um die Überprüfung und Weiterentwicklung dieser Ansätze im Rahmen eines Diskussionsforums gehen soll, wie es die diesem Sammelband zugrundeliegende Tagung darstellte.

Zwei vor wenigen Jahren publizierte Monographien möchte ich an den Anfang meiner Bestandsaufnahme stellen. Schon aufgrund ihrer provokanten Thesen und nicht gerade zimperlichen Beurteilung dessen, was bisher in der Investiturstreit-Forschung geleistet worden ist, fallen sie beide aus dem gewohnten Rahmen dessen, was üblicherweise mit dem Anspruch auf eine neue Sicht- und Herangehensweise verbunden ist. Ich meine die beiden Bücher von Johannes Fried und Gerd Althoff. Johannes Frieds „Streitschrift“ - so lautet der Untertitel seines Buches „Canossa Entlarvung einer Legende“ - wurde 2012 als Replik auf mehrstimmige Kritik seines bereits 2008 erstmals vorgebrachten Ansatzes publiziert. Im Kern geht es Fried darum, durch die Neubewertung der Quellenlage einerseits sowie einer Reihe von Plausibilitätserwägungen andererseits in der Begegnung von König und Papst in Canossa ein

Cambridge 2010, und die in Anm. 3 genannten Beiträge; Claudia Zey, Der Investiturstreit. München 2017.

7 Ludger Körntgen, Der Investiturstreit und das Verhältnis von Religion und Politik im Frühmittelalter, in: Richard Bonney / Franz Bosbach / Thomas Brockmann (Hrsg.), Religion und Politik in Deutschland und Großbritannien = Religion and Politics in Britain and Germany. (Prinz-Albert-Studien 19) Berlin 2013, 89-116, bes. $114 \mathrm{f}$.

8 Stuart Airlie, A View from Afar. English Perspectives on Religion and Politics in the Investiture Conflict, in: Bonney/Bosbach/Brockmann (Hrsg.), Religion und (wie Anm. 7), 71-88. 
von langer Hand geplantes Friedenstreffen zu sehen, das an der Unversöhnlichkeit der Fürsten und widrigen Umständen gescheitert sei ${ }^{9}$. Gerd Althoff arbeitete parallel dazu an einer Abhandlung zu den theoretischen Grundlagen des Amtsverständnisses der gregorianischen Reformer, die er 2013 als Monographie mit dem Titel „,Selig sind, die Verfolgung ausüben'. Päpste und Gewalt im Hochmittelalter“ publizierte, nachdem er seine Überlegungen bereits 2010 öffentlich gemacht hatte ${ }^{10}$. Beide haben sich in den vergangenen Jahrzehnten größte Verdienste um die methodische Durchdringung und Neuausrichtung unseres Fachs erworben, Johannes Fried unter anderem durch seine Forschungen zur oberitalienischen Rechts- und Gelehrtentradition und in letzter Zeit durch seine Erörterungen zur historischen Memorik, in die sich auch seine Canossa-

9 Johannes Fried, Canossa. Entlarvung einer Legende. Eine Streitschrift. Berlin 2012. Die auch vehement über die Frankfurter Allgemeine Zeitung ausgetragenen Forschungskontroverse hat Patrick Bahners unter dem Titel „Nach Canossa gehen wir zurück“ in der Frankfurter Allgemeinen Zeitung (F.A.Z.) vom 02.09.2015, N 3 (Druckausgabe) grob nachgezeichnet. Sie begann mit einem sechzigseitigen Aufsatz von Johannes Fried, Der Pakt von Canossa. Schritte zur Wirklichkeit durch Erinnerungsanalyse, in: Wilfried Hartmann / Klaus Herbers (Hrsg.), Die Faszination der Papstgeschichte. Neue Zugänge zum frühen und hohen Mittelalter. (Forschungen zur Kaiser- und Papstgeschichte des Mittelalters. Beihefte zu J. F. Böhmer, Regesta Imperii 28) Köln 2008, 133-197; zusammengefasst in einem Artikel der F.A.Z.vom 28.01.2009, N 4 (Druckausgabe) „Wir sollten nach Canossa gehen und die Legende vergessen. König Heinrich auf den Knien vor dem Papst? Ein Schlüsselereignis der europäischen Geschichte? Der Moment, in dem sich Staat und Kirche trennten? Alles falsch“. Eine Woche zuvor hatte bereits Oliver Jungen den Artikel von Fried wohlwollend vorbereitet, nachdem er offenbar bei der Ehrenpromotion von Johannes Fried in Aachen zugegen war (F.A.Z., 21.01.2009, N 3 [Druckausgabe]: „Geschichtsschreibung unter Eiweißzufuhr. Die Ehrenpromotion als Beitrag zur Forschung: Johannes Fried erschüttert in Aachen den Mythos vom Kampf der politisch-theologischen Giganten im Jahre 1077 zu Canossa."). In diesem Artikel bezeichnet Jungen Frieds 2008 erschienene Abhandlung als sensationell und die von ihm entworfene Version des Geschehens als in sich stimmiger. Die Sichtweise Frieds verurteilte Gerd Althoff energisch in einem Leserbrief in der F.A.Z. vom 28.02.2008, 38 (Druckausgabe) ,Falsche Memorik statt klassischer Methodik“ und in einem Beitrag für DAMALS 41, Heft 5, 2009, 59-61 „Kein Gang nach Canossa“ als missverständlich, auf selektiver Auswahl der Quellen beruhend und im Ergebnis willkürlich. Dieses scharfe Urteil Althoffs führte dazu, dass Fried ihn in der 2012 erschienenen Streitschrift nicht mehr mit Namen, sondern als „Leserbrief-Autor“ oder „Damals-Autor“ titulierte. Erfreut über die Verlässlichkeit der Fried-Althoff-Kontroverse zeigte sich Jürgen Kaube in seiner Würdigung von Johannes Fried zu dessen 70. Geburtstag in der F.A.Z. vom 21.05. 2012, 30 (Druckausgabe) „Kritiker der Erinnerung“, während er in der Würdigung von Gerd Althoff zu dessen 70. Geburtstag auf diesen Streit nur noch indirekt einging (F.A.Z., 08.07.2013, 32 [Druckausgabe]: „Wenn Herrscher weinen wollen. Der die Zeugen getrennt verhört: Fakt und Fiktion in der Geschichte des Mittelalters"). Noch stärker im Detail als Althoff kritisierte Steffen Patzold das methodische Vorgehen Frieds: Steffen Patzold, Gregors Hirn. Zu neueren Perspektiven der Forschung zur Salierzeit, in: Geschichte für heute. Zeitschrift für historisch-politische Bildung 4, Heft 2: Herrschaft im Hochmittelalter. Die Salier (2011), 5-19; hierin auch der Verweis auf ein weiteres Presseecho zu Frieds Thesen in der Tagespresse (5). Zeitgleich mit Frieds Streitschrift erschien 2012 der aus einer Ringvorlesung hervorgegangene Aufsatzband Canossa. Aspekte einer Wende (wie Anm. 2), in dem die Autoren mehr oder minder explizit zu einer ablehnenden Bewertung von Frieds Neudeutung kamen. Vgl. dazu die Besprechung von Klaus Herbers, Canossa zwischen Legende und Chiffre, in: F.A.Z. (19.07.2012), 30 (Druckausgabe).

10 Siehe unten die Anm. 19-23. 
Monographie einordnen lässt, sowie jüngst durch eine monumentale Biographie Karls des Großen ${ }^{11}$. Gerd Althoff steht dagegen maßgeblich für den Anstoß, Konflikte einerseits sowie Rituale, Gesten und weitere Formen nonverbaler Kommunikation andererseits zum Gegenstand einer breiten Forschungsrichtung der deutschsprachigen Mediävistik gemacht zu haben. Zentraler Gegenstand des ritualgeschichtlichen Ansatzes von Gerd Althoff war vornehmlich das römisch-deutsche Königtum der Ottonen und Salier. Heinrich IV. wurde von ihm mit einem Sammelband und mit einer kritischen Biographie bedacht ${ }^{12}$.

Das Echo auf den Band von Johannes Fried ist bisher breiter ausgefallen. Wenn man die positive Würdigung durch Michael Borgolte in der Frankfurter Allgemeinen Zeitung außer Acht lässt ${ }^{13}$, hat die Zunft bei allem Respekt für den Versuch, eines der bekanntesten Ereignisse des Mittelalters neu zu deuten, mit nahezu einhelliger Ablehnung reagiert ${ }^{14}$. Es soll aber nicht um das Für und Wider und den Gehalt der Canossa-These gehen, sondern um den methodischen Grundakkord, den Fried anstimmt. „Gedächtnisdeformationen“ lautet die Generalanklage, unter die Fried mittelalterliche wie moderne Historiographen gleichermaßen stellt und damit die Errungenschaften historischer Quellenkritik, deren zentrale Elemente Vergleich und

11 Johannes Fried, Der Schleier der Erinnerung. Grundzüge einer historischen Memorik. München 22012; ders., Karl der Große. Gewalt und Glaube. Eine Biographie. München 2013.

12 Gerd Althoff, Heinrich IV. (Gestalten des Mittelalters und der Renaissance) Darmstadt 2006; ders. (Hrsg.), Heinrich IV. (VuF 69) Ostfildern 2009.

13 Michael Borgolte, Ein Bußgang? Aber nein, ein Friedensfest?, in: F.A.Z. (21.06.2012), 34 (Druckausgabe): „Kein Zweifel: Johannes Fried hat eine neue und umstürzende Deutung der Vorgänge um Canossa mit einer in sich stimmigen Argumentation vorgelegt, die kein ernst zu nehmender Historiker vom Tisch wischen kann. Man mag bedauern, dass er dies in einer Streitschrift getan hat, die seine Gegner zu wenig überlegten Repliken herausfordern könnte. Deren Anspruch muss aber sein, Fried auf dem neuen Feld der „Memorik“ zu widerlegen.“

14 Ohne Anspruch auf Vollständigkeit vgl. neben dem in Anm. 2 genannten Sammelband die frei im Internet zugängliche, sehr persönlich gehaltene Besprechung von Christian Schwaderer, Canossa und Gedächtniskritik, online: L.I.S.A. Das Wissensportal der Gerda Henkel Stiftung, 04.12. 2012, online: http://www.lisa.gerda-henkel-stiftung.de/canossa_und_gedaechtniskritik?nav_id=4105 (Zugriff: 18.11. 2018); das von Jürgen Dendorfer betreute sehepunkte-Forum: Canossa - keine Wende? Mehrfachbesprechung von Fried, Canossa, online: sehepunkte 13, 2013, Nr. 1, 15.01.2013, www.sehepunkte.de/ 2013/01/forum/canossa-keine-wende-brmehrfachbesprechung-von-johannes-fried-canossa-entlar vung-einer-legende-eine-streitschrift-berlin-2012-163/, mit Rezensionen von Matthias Becher, HansWerner Goetz, Ludger Körntgen und Claudia Zey (Zugriff: 18.11.2018); Kathleen G. Cushing, Rez. von: Fried, Canossa, in: German Historical Institute London Bulletin, 35 (2013), 94-98, online: http://recen sio.net/r/20f0d6c97c004c75a2dab053541f2da3 (Zugriff: 18.11.2018); außerdem Rudolf Schieffer, Rez. von: Fried, Canossa, in: DA 69 (2013), 292, und noch einmal verschärft im Vergleich zu seinen Äußerungen von 2011: Steffen Patzold, Frieds Canossa. Anmerkungen zu einem Experiment, in: Geschichte für heute. Zeitschrift für historisch-politische Bildung 6, Heft 2: Canossa (2013), 5-39. Der Vielzahl von ablehnenden Stimmen aus der Mittelalter-Forschung pflichtet auch Bahners, Canossa (wie Anm.9) bei. Die profundeste Kritik auf der Basis philologischer Quellenstudien äußerte Ernst-Dieter Hehl, Gregor VII. und Heinrich IV. in Canossa 1077. Paenitentia - absolutio - honor. (MGH Studien und Texte 66) Wiesbaden 2019. 
umfassende Kontextualisierung sind, beiseiteschiebt, um geographische und zeitliche Nähe als alleinige Qualitätsmerkmale der Quellenlage in Anschlag zu bringen mit dem Ziel, eine weitgehend faktische Rekonstruktion der Vorgänge in und um Canossa zu bieten.

Was er letztlich beweisen wollte, nämlich dass Canossa nicht das von der Forschung vermeintlich stilisierte Wende-Ereignis ist, für das es zu Beginn des 20. Jahrhunderts noch gehalten wurde ${ }^{15}$, haben andere längst plausibel gemacht ${ }^{16}$. Auch der Canossa-Hype von 2006/07 war nicht dazu angetan, die Herrscherbuße auf der Burg zum Kulminationspunkt der gesamten Auseinandersetzung zu stilisieren, sondern als Chiffre für tiefgreifende Veränderungen in Kirche und Gesellschaft $\mathrm{zu}$ begreifen. In dieser Zuschreibung wird Canossa auch weiterhin hoch im Kurs stehen ${ }^{17}$.

Gerd Althoff hat mehrfach auf die Canossa-Thesen von Johannes Fried reagiert, zum einen in Auseinandersetzung mit dem von Fried herangezogenen Quellenmaterial $^{18}$ zum anderen durch eine Sichtung der Bibelstellen und Kirchenväterzitate, auf welche sich die Kirchenreformer im Kampf gegen die Reformgegner beriefen. Zum Vortrag brachte Althoff seine Überlegungen zur Gewalt-Theorie des Reformpapsttums bereits 2010 auf dem wissenschaftlichen Kolloquium zu Ehren des 65. Geburtstags von Stefan Weinfurter. In verkürzter Form erschien seine Festrede 2010 in der Frankfurter Allgemeinen Zeitung ${ }^{19}$, wurde dann 2012 in einer mit wenigen Anmerkungen verse-

15 Vgl. Helmut Kämpf (Hrsg.), Canossa als Wende. Ausgewählte Aufsätze zur neueren Forschung. (Wege der Forschung 12) Darmstadt 1963, mit Beiträgen von Anton Mayer-Pfannholz, Leone Tondelli, Albert Brackmann, Carl Erdmann, Johannes Haller, Augustin Fliche und Henry-Xavier Arquillière aus der Zeit zwischen 1927 und 1952. Dieser Sammelband hat die Sichtweise auf Canossa als Wendeereignis maßgeblich geprägt. Den Wende-Begriff hatte Anton Mayer-Pfannholz, Die Wende von Canossa. Eine Studie zum Sacrum Imperium, in: Hochland 30 (1932/33), 385-404, ND in: Die Wende von Canossa, 1-26) in die Forschungsdiskussion eingebracht. Vgl. dazu auch Wolfgang Hasberg / Hermann-Josef Scheidgen, Canossa. Aspekte einer Wende, in: dies. (Hrsg.), Canossa (wie Anm. 2), 7-13, hier 7.

16 Bereits Carl Mirbt, Die Publizistik im Zeitalter Gregors VII. Leipzig 1894, 198 bemerkte, dass „die Bussfahrt Heinrichs IV. nach Canossa (...) für die Zeitgenossen weder sensationell noch pikant“ war. Rudolf Schieffer, Worms, Rom und Canossa (1076/77) in zeitgenössischer Wahrnehmung, in: HZ 292 (2011), 593-612 zeigt anhand der zeitgenössischen Geschichtsschreibung, dass die Kenntnis vom „Bußgang Heinrichs IV. (...) auf die salische Reichsgeschichte beiderseits der Alpen (beschränkt blieb), an der Westeuropa keinen Anteil hatte.“ (611); auch ders., Investiturstreit im Bilde (wie Anm. 6). Oliver Münsch, Fortschritt durch Propaganda? Die Publizistik des Investiturstreits zwischen Tradition und Innovation, in: Jarnut/Wemhoff (Hrsg.), Vom Umbruch zur Erneuerung (wie Anm. 1), 151-167, konstatiert die marginale Rolle von Canossa in den Streitschriften (165 f.).

17 Vgl. Stefan Weinfurter, Canossa als Chiffre. Von den Möglichkeiten historischen Deutens, in: Hasberg / Scheidgen (Hrsg.), Canossa (wie Anm. 2), 124-140. Die Eingabe von „Canossa“ im OPAC der Regesta Imperii führt zu 642 Treffern (Zugriff: 18.11.2018). Davon zielt der geringere Teil auf Mathilde von Canossa und andere Canusiner, der größere auf Canossa als Ereignis bzw. als Schlagwort für den Investiturstreit. Der „Investiturstreit“ bringt es dagegen nur auf 413 Treffer (Zugriff: 18.11.2018).

18 Siehe die oben in Anm. 9 genannten Publikationen.

19 Gerd Althoff, Selig sind die, die Verfolgung ausüben, in: F.A.Z. (28.12.2010), N 4 (Druckausgabe). 
henen Fassung in einem Sammelband zu Canossa publiziert ${ }^{20}$, in dem sich die Autoren kritisch mit Frieds Thesen auseinandersetzten, sowie ein Jahr später in einer dichter belegten Fassung in dem aus dem Festkolloquium hervorgegangenen Band ${ }^{21}$. Im selben Jahr legte Gerd Althoff die zur Monographie angewachsene Abhandlung zu Päpsten und Gewalt im Hochmittelalter mit dem Quellenzitat „Selig sind, die Verfolgung ausüben“ als Haupttitel vor ${ }^{22}$. Eine weitere Replik auf Frieds Canossa-Thesen mit der Betonung des eigenen Ansatzes folgte 2014 in den Frühmittelalterlichen Studien ${ }^{23}$.

Markanter Aufhänger von Althoffs Untersuchung ist ein Zitat aus einer der engagiertesten progregorianischen Streitschriften, dem um 1085 entstandenen „Liber ad amicum“ Bischof Bonizos von Sutri ${ }^{24}$. Bonizo legte dem Kirchenlehrer Augustinus zu dessen Auslegung der Bergpredigt fälschlich das Zitat in den Mund, dass auch die selig seien, die um der Gerechtigkeit willen Verfolgung ausüben, ebenso wie diejenigen, die um der Gerechtigkeit willen Verfolgung erleiden ${ }^{25}$. Althoff sieht in dieser und anderen Stellen aus dem Schrifttum Gregors VII. selbst, seiner Anhänger und Nachfolger, welche sich hauptsächlich auf kämpferische Belegstellen aus dem Alten Testament beriefen, eine neue Theorie begründet, mit der die Ausübung von physischer Gewalt für die Durchsetzung der Kirchenreform und des päpstlichen Primatsanspruchs legitimiert werden sollte. In dieser „für moderne Christen wohl schockierenden Fremdartigkeit“"26 päpstlichen Gedankenguts, die dem christlichen Gebot der Friedens- und Feindesliebe diametral zuwiderlief, macht Althoff den Wurzelgrund für den bis heute waltenden päpstlichen Zentralismus im Innern der katholischen Kirche und das schwierige Verhältnis zu anderen Religionen aus, zumal die Gräueltaten der Kreuzfahrer bei der Eroberung von Jerusalem 1099 im kollektiven Gedächtnis der islamischen Welt bis zum heutigen Tag präsent seien. Der internationalen historischen Forschung, die sich eingehend mit dem Reformprozess des 11. Jahrhunderts auseinandergesetzt hat, darunter Carl Erdmann, Gerd Tellenbach, Walter Ullmann, Ian Stuart

20 Gerd Althoff, Zu den Grundlagen des Gregorianischen Amtsverständnisses, in: Hasberg/Scheidgen (Hrsg.), Canossa (wie Anm. 2), 73-88 mit den Anm. 210.

21 Gerd Althoff, Päpstliche Autorität im Hochmittelalter, in: Hubertus Seibert / Werner Bomm / Verena Türck (Hrsg.), Autorität und Akzeptanz. Das Reich im Europa des 13. Jahrhunderts. Ostfildern 2013, $253-265$.

22 Gerd Althoff, „Selig sind, die Verfolgung ausüben“. Päpste und Gewalt im Hochmittelalter. Ostfildern 2013. Vgl. auch die Studie von Monika Suchan, Macht verschafft sich Moral? Gewalt in der Politik der Reformpäpste. (Beiträge zur Friedensethik 34) Stuttgart 2002.

23 Gerd Althoff, Das Amtsverständnis Gregors VII. und die neue These vom Friedenspakt in Canossa, in: Frühmittelalterliche Studien 48 (2014), 261-276.

24 Bonizo von Sutri, Liber ad amicum. Ed. Ernst Dümmler, in: MGH Ldl 1. Hannover 1891, 568-620; vgl. Thomas Förster, Bonizo von Sutri als gregorianischer Geschichtsschreiber. (MGH Studien und Texte 53) Hannover 2011.

25 Bonizo, Liber ad amicum. Ed. Dümmler (wie Anm. 24), 619, lib. 8: Idem de sermone Dei habito in monte, cum de beatitudinibus et venisset ad Beati qui persecutionem paciuntur propter iustitiam [Matth. 5,10], equaliter dixit beatos eos, qui persecutionem inferunt propter iusticiam, acsi qui persecutionem paciuntur propter iusticiam.

26 Althoff, „Selig sind, die Verfolgung ausüben“ (wie Anm. 22), 2. 
Robinson oder Herbert E. J. Cowdrey, bescheinigt Althoff Betriebsblindheit, da sie sich mehr mit den intellektuellen und religiösen Fragen beschäftigt hätten als mit der nach seiner Sicht der Dinge zentralen Gewaltfrage. Diese Gewaltfrage aufzuarbeiten und in den Kontext aktueller Diskurse zu stellen, macht sich Althoff zum Ziel, indem er in sechs grob chronologisch geordneten Kapiteln die Schriften der Gregorianer und ihrer Gegner sichtet und nach dem Einfluss der Gewaltdiskurse auf das Kirchenrecht sucht. Zwei weitere Abschnitte dienen dem systematischen Überblick über Gewaltrhetorik und Gewalt sowie einem Ausblick über die von den Reformern propagierte „Häresie des Ungehorsams“ im 12. und 13. Jahrhundert, bevor er die Ergebnisse bündelt und in einen allgemeineren Horizont stellt.

Mit diesem Buch kehrt Althoff zu dem von ihm lange beackerten Feld der Konfliktforschung zurück, allerdings mit stark verändertem Blickwinkel: Weg von den Konflikten zwischen Königen und Großen sowie ihrer ritualisierten Beilegung hin zur Gewaltrhetorik der Kirchenreformer, ihren handgreiflichen Folgen im Mittelalter und ihren mentalen Folgen für das Verhältnis von Christentum und Islam bis in die heutige Zeit.

Dass die Resonanz auf dieses Buch weitgehend positiv ausfällt, hat viel mit dessen Aktualitätsbezug, aber auch mit dem ideengeschichtlichen Ansatz und der quellenbasierten Argumentationsstruktur zu tun ${ }^{27}$. Gegen die Stringenz der Argumentation, zu der auch in diesem Buch überzogenen Fachschelte und zu dem gelegentlich überstrapazierten Aktualitätsbezug lassen sich aber auch einige Einwände erheben. Es seien hier nur wenige Punkte angedeutet: Die von den Reformern benutzten Zitate aus dem Alten Testament werden von Althoff nahezu durchgehend als unverblümte Handlungsanweisung verstanden, nicht aber auf ihren allegorischen Sinn hin befragt. Demgegenüber wird die Frage, wo und in welchen Kontexten es zu konkreter Gewaltanwendung kam, nicht weiter thematisiert. Althoff verwendet den Gewalt-Begriff weitgehend undifferenziert, die lateinischen Worte - etwa potestas und persecutio - werden weder lexikalisch noch semantisch verortet. In einem sehr einfachen Schwarzweiß-Schema wird zwischen den militanten Gregorianern und den friedensliebenden heinricianischen Parteigängern unterschieden, was auch angesichts des Bildes, das Althoff noch vor wenigen Jahren von Heinrich IV. gezeichnet hat,

27 Vgl. wiederum ohne Anspruch auf Vollständigkeit die Rezensionen von Rudolf Schieffer, Rez. von: Althoff, „Selig sind, die Verfolgung ausüben“, in: DA 69 (2013), 755; Martin Ohst, Rez. von: Althoff, „Selig sind, die Verfolgung ausüben“, online: H-Soz-Kult, 28.08.2013, https://www.hsozkult.de/publicationre view/id/rezbuecher-20730 (Zugriff: 18.11.2018); Bernd Schneidmüller, Rez. von: Althoff, „Selig sind, die Verfolgung ausüben“ (wie Anm. 22), in: DAMALS 07, 2013, online: https://www.wissenschaft.de/rezen sionen/buecher/selig-sind-die-verfolgung-ausueben-paepste-und-gewalt-im-hochmittelalter/ (Zugriff: 18.11.2018); Peter Dinzelbacher, Rez. von: Althoff, „Selig sind, die Verfolgung ausüben“, in: ZhF 41 (2014), 473-475, online: https://www.recensio.net/rezensionen/zeitschriften/zeitschrift-fuer-histori sche-forschung/41-2014/3/ReviewMonograph926485538 (Zugriff: 18.11.2018); Claire de Cazanove, Rez. von: Althoff, „Selig sind, die Verfolgung ausüben“, Revue de l'IFHA, online: 14.04.2015, https://jour nals.openedition.org/ifha/8189 (Zugriff: 17.09.2015). 
verblüffen muss ${ }^{28}$. Überhaupt wird allgemein der Eindruck vermittelt, die Gregorianer hätten Unfrieden und Gewalttätigkeit in eine friedvolle Gesellschaft gebracht. Die Behauptung, die etablierte Forschung, unterteilt in Apologeten und Denunzianten der Reformer, habe sich Althoffs Sichtweise auf das Reformpapsttum bislang verschlossen, trifft Carl Erdmann und andere zu Unrecht, da sie den kämpferischen Impetus der Kirchenreformer um Gregor VII. keineswegs verschwiegen haben, wenn sie ihn auch nicht zum Hauptgegenstand ihrer Darstellungen machten ${ }^{29}$. Auf den letzten Seiten seiner Studie hat Althoff vieles von dem, was er zuvor mit großer Verve vertreten hat, wieder relativiert ${ }^{30}$.

Ohne sie im Einzelnen namhaft zu machen, hat Gerd Althoff eine ganze Reihe von Forschungsfeldern zum Investiturstreit in seinem Band gebündelt. Mit der Frage nach dem Selbstverständnis der Akteure nimmt er eine bewährte Münsteraner Forschungstradition wieder auf, die 1972 mit der Arbeit von Christian Schneider zum „Prophetischen Sacerdotium und zum heilsgeschichtlichen Regnum im Dialog“ begonnen und von Jörgen Vogel 1983 mit der Untersuchung zu „Gregor VII. und Heinrich IV. nach Canossa. Zeugnisse ihres Selbstverständnisses“ fortgesetzt worden ist ${ }^{31}$. Auch wenn diese Arbeiten auf den Pontifikat Gregors VII. beschränkt blieben und vornehmlich Briefe und Urkunden der beiden Kontrahenten zum Gegenstand hatten, zeigten besonders Christian Schneiders Ergebnisse, wie wichtig die Erforschung des Argumentariums der Akteure für das Verständnis des politischen Handelns beider Seiten ist ${ }^{32}$. Schneider konstatierte im Übrigen als Resultat seiner Briefanalyse, dass sich Gregor und Heinrich „der gleichen Sprache“ bedienten, „um ihr Gottesgnadentum zu behaupten“"33. Ein Befund, dem mit Verweis auf die unterschiedliche Intention der identischen Wortwahl von kundiger Stimme widersprochen worden ist ${ }^{34}$, was aber zeigt, dass die Rechtfertigungsstrategien beider Seiten keineswegs so weit auseinander lagen, wie Althoff in seiner neuesten Veröffentlichung glauben machen will.

28 Siehe oben Anm. 12.

29 Vgl. Carl Erdmann, Die Entstehung des Kreuzzugsgedankens. (Forschungen zur Kirchen- und Geistesgeschichte 6) Stuttgart 1935. Viele weitere Beispiele wären zu nennen, stellvertretend Ian S. Robinson, Gregory VII and the Soldiers of Christ, in: History 58 (1973), 169-192. Althoff, „Selig sind, die Verfolgung ausüben“ (wie Anm. 22), 14-30 würdigt diese Darstellungen zwar in der Einleitung seines Buchs, sieht die Gewaltthematik aber nicht hinreichend pointiert.

30 Vgl. Althoff, „Selig sind, die Verfolgung ausüben“ (wie Anm. 22), 215-229.

31 Christian Schneider, Prophetisches Sacerdotium und heilsgeschichtliches Regnum im Dialog 10731077. Zur Geschichte Gregors VII. und Heinrichs IV. (Münstersche Mittelalter-Schriften 9) München 1972; Jörgen Vogel, Gregor VII. und Heinrich IV. nach Canossa. Zeugnisse ihres Selbstverständnisses. (Arbeiten zur Frühmittelalterforschung 9) Berlin 1983.

32 Vgl. auch die methodisch ähnlich ausgerichtete Studie von Roland Zingg, Die Briefsammlungen der Erzbischöfe von Canterbury, 1070 - 1170. Kommunikation und Argumentation im Zeitalter der Investiturkonflikte. (Zürcher Beiträge zur Geschichtswissenschaft 1) Köln 2012; ders., Streit ohne Streitschriften? Die englische Investiturproblematik im Spiegel der Briefsammlungen Lanfrancs und Anselms von Canterbury, in: Hartmann (Hrsg.), Brief und Kommunikation (wie Anm. 5), 157-174. 33 Schneider, Sacerdotium (wie Anm. 31), 164.

34 Vgl. Wilfried Hartmann, Rez. von: Schneider, Prophetisches Sacerdotium, in: DA 29 (1973), 286. 
Die Betrachtung der in den Schriften ausgetauschten beziehungsweise gegeneinander eingesetzten Argumente ordnet sich ein in den großen Forschungsdiskurs um die Publizistik im Investiturstreit, den noch im 19. Jahrhundert Carl Mirbt mit seinem 1894 erschienen Band zur „Publizistik im Zeitalter Gregors VII.“ begründet hat $^{35}$. Über den Begriff der Publizistik ist seitdem in zahlreichen Beiträgen räsoniert worden $^{36}$. Auch wurden die in den „Libelli de lite“ vereinigten Schriften vielfach auf ihren theologischen und historischen Kern, auf ihre (frühscholastische) Methodik und vor allem auf ihre Bezüge untereinander untersucht. Horst Fuhrmann mit seinem Schülerkreis steht ebenso für diesen Ansatz wie die englischsprachige Forschung, vor allem in Gestalt von Ian Stuart Robinson, der die Arbeitsweise der süddeutschen Gregorianer bis auf die Handschriften hinunter unter die Lupe genommen hat ${ }^{37}$. Einen

35 Mirbt, Publizistik (wie Anm. 16).

36 Vgl. Josef Benzinger, Zum Wesen und zu den Formen von Kommunikation und Publizistik im Mittelalter. Eine bibliographische und methodologische Studie, in: Publizistik 15 (1970), 295-318; Hans-Werner Goetz, Geschichte als Argument. Historische Beweisführung und Geschichtsbewusstsein in den Streitschriften des Investiturstreits, in: HZ 245 (1987), 31-70; ders., Fälschung und Verfälschung der Vergangenheit. Zum Geschichtsbild der Streitschriften des Investiturstreits, in: Horst Fuhrmann (Hrsg.), Fälschungen im Mittelalter. Internationaler Kongreß der Monumenta Germaniae Historica. München, 16.-19. September 1986, Bd. 1: Kongreßakten und Festvorträge. Literatur und Fälschung. (MGH Schriften 33.1) Hannover 1988, 165-188; Monika Suchan, Publizistik im Zeitalter Heinrichs IV. Anfänge päpstlicher und kaiserlicher Propaganda im Investiturstreit, in: Karel Hruza (Hrsg.), Propaganda, Kommunikation und Öffentlichkeit im Mittelalter. (Forschungen zur Geschichte des Mittelalters 6) Wien 2002, 29-46; darin auch der grundlegende Beitrag von Karel Hruza, Propaganda, Kommunikation und Öffentlichkeit im Mittelalter, 9-28; Münsch, Fortschritt (wie Anm. 16); Thomas Wetzstein, Von der Unmöglichkeit zu kommunizieren. Briefe, Boten und Kommunikation im Investiturstreit, in: Hartmann (Hrsg.), Brief und Kommunikation (wie Anm. 5), 43-68; Christian Heinrich, Was versteht man unter einer Streitschrift? Vorschlag einer Neudefinition, in: ebd., 91-102; Gerhard Lubich, Die „Öffentlichkeiten“ von Heinrich IV. und Heinrich V. Zum Bild ihrer Herrschaftsgestaltung in Geschichtsschreibung, Briefen und Urkunden, in: ebd., 129-145.

37 Vgl. Karl Joseph Leyser, The Polemics of the Papal Revolution, in: Beryl Smalley (Hrsg.), Trends in Medieval Political Thought. Oxford 1965, 42-64; ders., Am Vorabend der ersten europäischen Revolution. Das 11. Jahrhundert als Umbruchszeit, in: HZ 257 (1993), 1-26; Wilfried Hartmann, Manegold und die Anfänge der Frühscholastik, in: DA 26 (1970), 47-149; Jürgen Ziese, Historische Beweisführung in den Streitschriften des Investiturstreits. (Münchener Beiträge zur Mediävistik und RenaissanceForschung 8) München 1972; Horst Fuhrmann, „Volkssouveränität“ und „Herrschaftsvertrag“ bei Manegold von Lautenbach, in: Sten Gagnér / Hans Schlosser / Wolfgang Wiegand (Hrsg.), Festschrift für Hermann Krause. Köln / Wien 1975, 21-42; Ian S. Robinson, The „colores rhetorici“ in the Investiture Contest, in: Traditio 32 (1976), 209-238; ders., Authority and Resistance in the Investiture Contest. The Polemical Literature of the Late Eleventh Century. Manchester 1978; ders., The Friendship Network of Gregory VII, in: History 63 (1978), 1-22; ders., Zur Arbeitsweise Bernolds von Konstanz und seines Kreises. Untersuchungen zum Schlettstätter Codex 13, in: DA 34 (1978), 1-122; Claudia Märtl, Regensburg in der geistigen Auseinandersetzung des Investiturstreits, in: DA 42 (1986), 145-191; Ian S. Robinson, Bernold von Konstanz und der gregorianische Reformkreis um Bischof Gebhard III., in: Freiburger Diözesan-Archiv 109 (1989), 155-188; Tilman Struve, Das Problem der Eideslösung in den Streitschriften des Investiturstreits, in: ZRG Kan. Abt. 75 (1989), 107-132; Wilfried Hartmann, Rhetorik und Dialektik in der Streitschriftenliteratur des 11./12. Jahrhunderts, in: Johannes Fried (Hrsg.), Dia- 
spezifischen Münsteraner Ansatz markierte dabei Monika Suchans Dissertation von 1997, welche die Schriftlichkeit als Bestandteil der Konfliktaustragung zwischen König Heinrich IV. und seinen Gegnern ins Zentrum rückte. Suchans Untersuchungen wurden in der Methode als innovativ, im Ergebnis aber als korrekturbedürftig eingeschätzt ${ }^{38}$.

Eine wichtige Wiederbelebung fand die Diskussion um die Öffentlichkeitswirksamkeit des Schrifttums im Investiturstreit in jüngerer Zeit durch das 2007 veröffentlichte, fast 800 Seiten starke Opus von Leidulf Melve „Inventing the Public Sphere. The Public Debate during the Investiture Contest“ für die Zeit von 1030 bis $1122^{39}$. Melve sieht in den Streitschriften die erste öffentliche Debatte des Mittelalters, die er minutiös analysiert und anhand theoretischer Konzepte, besonders des Öffentlichkeitsbegriffs von Jürgen Habermas, kategorisiert. Die Streitschriften werden nach ihrer Entstehungszeit geordnet und in drei Zeitabschnitte eingeteilt. Für den ersten Zeitraum von 1030 bis 1073 beobachtet Melve noch keine eindeutigen Parteiungen und eine nur von einer kleinen Elite ausgetragene Debatte. Erst in der zweiten von 1073 bis 1099 reichenden Phase hätten der polemische Charakter der Schriften, aber auch ihre zunehmende Komplexität, die Veränderung des Argumentariums von „moralischtheologischen Argumenten“ hin zu ,juristischen und historischen Begründungsstrategien“, die Erweiterung des Adressatenkreises auch auf dem Wege mündlicher Verbreitung und die Vorreiterrolle der päpstlichen und kaiserlichen Kanzleien für eine semi-institutionelle Öffentlichkeit gesorgt. Hingegen sei die Spätphase von 1099 bis

lektik und Rhetorik im früheren und hohen Mittelalter. Rezeption, Überlieferung und gesellschaftliche Wirkung antiker Gelehrsamkeit vornehmlich im 9. und 12. Jahrhundert. (Schriften des Historischen Kollegs. Kolloquien 27) München 1997, 723-795; ders., Toleranz im Investiturstreit, in: Alexander Patschovsky / Harald Zimmermann (Hrsg.), Toleranz im Mittelalter. (VuF 45) Sigmaringen 1998, 27-51; ders., Wahrheit und Gewohnheit. Autoritätenwechsel und Überzeugungsstrategien in der späteren Salierzeit, in: Schneidmüller/Weinfurter (Hrsg.), Salisches Kaisertum (wie Anm. 6), 65-84.

38 Monika Suchan, Königsherrschaft im Streit. Konfliktaustragung in der Regierungszeit Heinrichs IV. zwischen Gewalt, Gespräch und Schriftlichkeit. (Monographien zur Geschichte des Mittelalters 42) Stuttgart 1997. Vgl. dazu Klaus Naß, Rez. von: Suchan, Königsherrschaft, in: DA 56 (2000), 707 f., mit Verweis auf die ausführlicheren Besprechungen von Rudolf Schieffer, Rez. von: Suchan, Königsherrschaft, in: RhVjbll 63 (1999), 358 f. und Wolfgang Eggert, Rez- von: Suchan, Königsherrschaft, in: MIÖG 107 (1999), 425 - 427. Zu weiteren einschlägigen Publikationen von Monika Suchan siehe die Anm. 22 und 36.

39 Leidulf Melve, Inventing the Public Sphere. The Public Debate during the Investiture Contest (c. 1030 -1122), 2 Bde. (Brill's Studies in Intellectual History 154.1-2) Leiden 2007. Vgl. außerdem ders., Intentional Ethics and Hermeneutics in the Libellus de symoniacis. Bruno of Segni as a Papal Polemicist, in: Journal of Medieval History 35 (2009), 77-96; ders. The Public Debate on Clerical Marriage in the Late Eleventh Century, in: The Journal of Ecclesiastical History 61 (2010), 688-706; ders., Performance, Argument, and Assembly Politics (ca. 1080 - ca. 1160), in: Marc Laureys / Roswitha Simons (Hrsg.), Die Kunst des Streitens. Inszenierung, Formen und Funktionen öffentlichen Streits in historischer Perspektive. (Super alta perennis. Studien zur Wirkung der Klassischen Antike 10) Göttingen 2010, 85-108; ders., ,... to distil the excellence of their genius“. Conceptions of Authorship in Eleventhand Twelfth-Century Polemical Literature, in: Slavica Rankovic / Ingvil Brügger Budal (Hrsg.), Modes of Authorship in the Middle Ages. (Papers in Medieval Studies 22) Toronto 2012, 133-150. 
1122 wieder durch weniger auf öffentliche Wirksamkeit gerichtete, aber dafür stärker institutionalisierte Debatten gekennzeichnet gewesen ${ }^{40}$. Bezogen auf den Öffentlichkeitsbegriff bleibt Melve letztlich vage, gelangt aber immerhin zu einem bedenkenswerten Modell für eine vormoderne Form von Öffentlichkeit, welches die Annahmen von Habermas relativiert ${ }^{41}$.

Etwa zur selben Zeit wie Leidulf Melve befasste sich auch Oliver Münsch mit der Publizistik des Investiturstreits zwischen Tradition und Innovation ${ }^{42}$. Mit einem eher kommunikationstheoretischen Ansatz sah er in der „Mobilisierung breiterer Schichten jenseits der Gelehrtenwelt durch geeignete propagandistische [d. h. polemische] Techniken“ die Neuartigkeit dieses Schrifttums und der Debatte überhaupt. Er verband seine Einsichten mit dem Postulat, „dass die Mediävistik einer Reflexion über mittelalterliche Bedingungen von Kommunikation jenseits von Ritualität und Symbolik bedarf und einen adäquaten Kommunikationsbegriff entwickeln sollte, der an den spezifisch mittelalterlichen Bedingungen von Öffentlichkeit orientiert ist“. Notwendig sei außerdem ,gerade vor dem Hintergrund zahlreicher neu entstandener Sammlungen im 11. Jahrhundert, eine stärkere Berücksichtigung der Kanonistik als Argumentationsreservoir für die Streitschriften“"43. Diese aus der Schule von Hubert Mordek nicht ganz unerwartete Forderung nach Einbeziehung von Rechtssammlun-

40 Vgl. die Rezensionen von Bee Yun, Rez.von: Melve, Inventing the Public Sphere, online: H-Soz-Kult, 01.10.2008, https://www.hsozkult.de/publicationreview/id/rezbuecher-10412 (Zugriff: 18.11.2018); Oliver Münsch, Rez. von: Melve, Inventing the Public Sphere, in: DA 65 (2009), 205 f.; Georg Strack, Rez. von: Melve, Inventing the Public Sphere, online: sehepunkte 9 (2009), Nr. 12, http://www.sehepunkte. de/2009/12/17232.html (Zugriff: 18.11.2018) (die Zitate aus dieser Besprechung).

41 Vgl. bes. die Kritik von Airlie, View (wie Anm. 8), 83 f. Überlegungen zu noch stark begrenzten Kommunikationsräumen im Investiturstreit finden sich auch bei Thomas Wetzstein, Canossa ein Wendepunkt in der Kommunikationsgeschichte?, in: Hasberg/Scheidgen (Hrsg.), Canossa (wie Anm. 2), 112-123. Zum Öffentlichkeitsbegriff bezogen auf das Spätmittelalter vgl. auch Martin Kintzinger / Bernd Schneidmüller (Hrsg.), Politische Öffentlichkeit im Spätmittelalter. (VuF 75) Ostfildern 2011.

42 Vgl. Oliver Münsch, Die Orthodoxa defensio imperialis. Ein Beitrag zur Publizistik des Investiturstreits, in: Thomas Martin Buck (Hrsg.), Quellen, Kritik, Interpretation. Festgabe zum 60. Geburtstag von Hubert Mordek. Frankfurt 1999, 135-154; ders., Tiersymbole und Tiervergleiche als Mittel der Polemik in Streitschriften des späten 11. Jahrhunderts, in: HJB 124 (2004), 3-43; ders., Das Bild Karls des Großen in der Publizistik des Investiturstreits, in: ders. / Thomas Zotz (Hrsg.), Scientia veritatis. Festschrift für Hubert Mordek zum 65. Geburtstag. Ostfildern 2004, 311-326; ders., Ein Streitschriftenfragment zur Simonie, in: DA 62 (2006), 619-630; ders., Neues zu Bernold von Konstanz, in: ZRG Kan. Abt. 92 (2006), 207-223; ders., Fortschritt (wie Anm. 16), 151-167; ders., Heuchlerischer Tyrann oder Opfer päpstlicher Willkür? Die Darstellung Heinrichs IV. in publizistischen Texten des Investiturstreits, in: Tilman Struve (Hrsg.), Die Salier, das Reich und der Niederrhein. Köln 2008, 173-205; ders., Hate Preachers and Religious Warriors. Violence in the Libelli de lite of the Late Eleventh Century, in: Gabriela Signori (Hrsg.), Dying for the Faith, Killing for the Faith. Old-Testament Faith-Warriors (1 and 2 Maccabees) in Historical Perspective. (Brill's Studies in Intellectual History 206) Leiden 2012, 161-176; ders., Gerüchte und ihre Verbreitung. Beobachtungen zur Propaganda im Investiturstreit, in: Hartmann (Hrsg.), Brief und Kommunikation (wie Anm. 5), 69-90.

43 Münsch, Fortschritt (wie Anm. 16), 159, $166 \mathrm{f}$. 
gen und ihrer handschriftlichen Tradition scheint mir allerdings bereits ein Kontinuum in der Erforschung der streitbedingten Schriftproduktion zu sein, welches auch für die historische Forschung nutzbar gemacht wurde ${ }^{44}$. Allerdings ist die Gefahr einer hermetischen Diskussion aufgrund des hohen Spezialwissens, welches man im Umgang mit den diversen Sammlungen braucht, recht hoch.

Eine fruchtbare Fortsetzung der an der Streitschriftenliteratur erprobten Ansätze liegt in der Heranziehung weiterer Quellengruppen, die per se auf eine stärkere Einbindung größerer Gruppen, auch jenseits der Gelehrtenkreise zielen. Damit sind in erster Linie Predigten gemeint, die man in einer offenen Definition auch als religiös motivierte Reden bezeichnen könnte ${ }^{45}$. Für das spätere Mittelalter, besonders im Kontext der Franziskaner- und Dominikaner-Forschung, längst als bedeutende Quellengattung erkannt, vielfach neu ediert und auf ihren argumentativen Gehalt hin untersucht ${ }^{46}$, sind sie für das Hochmittelalter, insbesondere für den Investiturstreit erst in den letzten Jahren wieder verstärkt in den Blick geraten ${ }^{47}$. Unter dem Begriff der „Oratorik“ hat Georg Strack die Reden und Predigten Gregors VII. durchmustert und auch das Wissen über die Kreuzzugspredigt Urbans II. in Clermont einer Relecture

44 Vgl. die bibliographischen Aufarbeitungen durch Lotte Kéry, Canonical Collections of the Early Middle Ages (ca. 400-1140). A Bibliographical Guide to the Manuscripts and Literature. (History of Medieval Canon Law.) Washington, DC 1999; Linda Fowler-Magerl, Clavis Canonum. Selected Canon Law Collections before 1140. Access with Data Processing. (MGH Hilfsmittel 21) Hannover 2005; siehe auch die in Anm. 37 genannten Publikationen von Wilfried Hartmann, zu denen weitere ergänzt werden könnten; Detlev Jasper, The Deposition and Excommunication of Emperors and Kings. A Collection of Historical Examples from the Investiture Conflict, in: Uta-Renate Blumenthal / Anders Winroth / Peter Landau (Hrsg.), Canon Law, Religion and Politics. Liber amicorum Robert Somerville. Washington, DC 2012, 199-214; Lotte Kéry, Recht im Dienst der Reform. Kanonistische Sammlungen der Reformzeit und ihre „Adressaten“, in: Hartmann (Hrsg.), Brief und Kommunikation (wie Anm. 5), 335-380.

45 Auf die Bedeutung der Predigten der Hirsauer Mönche für die Verbreitung der gregorianischen Propaganda verweist Münsch, Fortschritt (wie Anm. 16), 161; auch Melve, Inventing (wie Anm. 39), 102 f., schätzt die Bedeutung von volkssprachlichen Predigten zur Verbreitung der Polemiken im Investiturstreit hoch ein. Zur offenen Definition von Predigten vgl. Georg Strack, Oratorik im Zeitalter der Kirchenreform. Reden und Predigten Papst Gregors VII., in: ders. / Julia Knödler (Hrsg.), Rhetorik in Mittelalter und Renaissance. Konzepte - Praxis - Diversität. (Münchner Beiträge zur Geschichtswissenschaft 6) München 2011, 121-144, 122 Anm. 4.

46 Vgl. aus der reichhaltigen Literatur Michael Menzel, Predigt und Geschichte. Historische Exempel in der geistlichen Rhetorik des Mittelalters. (Archiv für Kulturgeschichte. Beiheft 45) Köln 1998; Johannes Schütz, Gelehrte Predigt als dominikanische Innovation. Anmerkungen zur Studienorganisation des Dominikanerordens im 13. Jahrhundert, in: Mirko Breitenstein (Hrsg.), Innovation in Klöstern und Orden des Hohen Mittelalters. Aspekte und Pragmatik eines Begriffs. (Vita regularis Abhandlungen 48) Berlin 2012, 247-262.

47 Vgl. Jochen Johrendt, Rusticano stilo? Papst und Rhetorik im 11. und 12. Jahrhundert, in: Florian Hartmann (Hrsg.), Cum verbis ut Italici solent suavibus atque ornatissimis. Funktionen der Beredsamkeit im kommunalen Italien / Funzioni dell'eloquenza nell'Italia comunale. (Super alta perennis. Studien zur Wirkung der Klassischen Antike 9) Göttingen 2011, 153-176. 
unterzogen ${ }^{48}$. Trotz der methodischen Problematik dieser meist nur mittelbar überlieferten und für die Schriftform stark stilisierten Reden, kann Strack auf verwandte Elemente mit der Streitschriftenliteratur hinweisen, wie etwa den Einsatz dieser Reden zur Stärkung der eigenen Anhängerschaft. Er konnte außerdem anhand der in Synodalprotokollen und Briefen tradierten Predigten zeigen, dass die päpstliche Oratorik weniger durch reiche rhetorische Ausschmückung als durch das Abarbeiten bestimmter Formalia geprägt war, vergleichbar mit dem Aufbau einer Papsturkunde und damit an klassischen rhetorischen Vorbildern orientiert ${ }^{49}$.

Das von Strack und anderen geöffnete Forschungsfeld ist weit, bedenkt man nur, in wie vielen Geschichtswerken die wörtliche Rede als persuasives Mittel eingesetzt wird. Ihr hoher Stilisierungsgrad hat sie als Quellen für die historische Forschung eher problematisch erscheinen lassen, doch bietet der Vergleich der rhetorischen bzw. oratorischen Mittel und Motive ein dem Umgang mit schriftlichen Quellen, besonders denjenigen in Briefform, vergleichbares Analyseraster. Es sollte zur Anwendung kommen, wenn es um zentrale Fragen des Investiturstreits geht, wie das Selbstverständnis der Protagonisten, die Argumentationsstrategien und deren Wirksamkeit bei Anhängern und Gegnern.

Insofern ist es auch sehr begrüßenswert, dass Florian Hartmann die sich von Oberitalien aus verbreitenden artes dictandi unter historischem Blickwinkel zum Gegenstand seiner Habilitationsschrift und weiterer flankierender Beiträge gemacht hat. Zwar gehört das Schwergewicht dieser Brieflehren - ,jene[s] Teil[s] der mittelalterlichen Rhetorik, der sich dem Verfassen von Briefen und anderen Prosadokumenten widmete“ - ins 12. und 13. Jahrhundert und sind inhaltlich vor allem an die kommunale Entwicklung gebunden, doch berühren die Anfänge seit dem Ende des 11. Jahrhunderts den Investiturstreit und auch die aus italienischer Feder stammenden Streitschriften ${ }^{50}$. In Erweiterung dieses Ansatzes hat Florian Hartmann im Jahr 2014

48 Strack, Oratorik (wie Anm. 45); ders., The Sermon of Urban II in Clermont and the Tradition of Papal Oratory, in: Medieval Sermon Studies 56 (2012), 30 - 45. In Weiterführung dieses Ansatzes veranstaltete Georg Strack im Juli 2013 einen Workshop am Münchner Center for Advanced Studies unter dem Titel: Rhetorik, Ritual und Recht. Reden und Predigten auf Kirchenversammlungen des Mittelalters (11.15. Jahrhundert). Vgl. außerdem ders., Antagonistische Positionen zur politischen Redekultur im 11. Jahrhundert. Benzo von Alba und Rangerius von Lucca, in: Hartmann (Hrsg.), Brief und Kommunikation (wie Anm. 5), 243-260.

49 Vgl. Strack, Oratorik (wie Anm. 45), 124-132.

50 Florian Hartmann, Ars dictaminis. Briefsteller und verbale Kommunikation in den italienischen Stadtkommunen des 11. bis 13. Jahrhunderts. (Mittelalter-Forschungen 44) Ostfildern 2013, 4; ders., Kunst des Schreibens (wie Anm. 4), 35-55; ders., Funktionen der Beredsamkeit im kommunalen Italien. Befunde und Probleme, in: ders. (Hrsg.), Cum verbis (wie Anm. 47), 9-26; ders., Multas quoque preces feret vobis inditus ordo virorum. Funktionen der ars dictaminis im kommunalen Italien, in: ebd., 111-134; ders., Decet ergo cives cum civibus concorditer vivere. Ideal und Identität in kommunalen Artes dictandi Oberitaliens, in: Strack/Knödler (Hrsg.), Rhetorik in Mittelalter und Renaissance (wie Anm. 45), 41-62; ders., Heinrich V. im Diskurs Bologneser Gelehrter, in: Gerhard Lubich (Hrsg.), Heinrich V. in seiner Zeit. Herrschen in einem europäischen Reich des Hochmittelalters. (Forschungen 
eine Tagung zu „Brief und Kommunikation im Wandel. Medien, Autoren und Kontexte in den Debatten des Investiturstreits“ veranstaltet, deren Beiträge 2016 publiziert worden sind ${ }^{51}$.

Noch einmal soll die Aufmerksamkeit auf die Protagonisten des Investiturstreits gelenkt werden. In den Büchern von Johannes Fried und Gerd Althoff, so unterschiedlich sie im Ergebnis ausfallen, geht es letztlich auch um die Funktionalität beziehungsweise Dysfunktionalität des Umfeldes von Kaiser und Papst, um die Angehörigen, die Berater, die näheren und ferneren Anhänger der einen wie der anderen Seite. Wohl und Wehe hing nicht allein von der Wirkmacht der Worte, der Argumente und Polemiken, ab, sondern von der Quantität und Qualität des Anhangs, der institutionellen Anbindung der Parteigänger und den damit wiederum verbundenen Einflussmöglichkeiten. Die hohe Bedeutung der Vernetzung von Personen und Institutionen ist für den Verlauf des Investiturstreits längst erkannt und immer wieder Gegenstand eingehender Untersuchungen gewesen. Der Band von Tilmann Schmidt über Alexander II. und die römische Reformgruppe seiner Zeit ${ }^{52}$, die Arbeiten von Ian Stuart Robinson über das südwestdeutsche „Friendship-Network“ Gregors VII. ${ }^{53}$ oder Stefan Weinfurters Wortmeldung zu Heinrich V. und dessen Beratern in der Frühzeit seiner Herrschaft ${ }^{54}$ können hier exemplarisch genannt werden. Das päpstliche Umfeld ist dabei um einiges besser durchleuchtet als das königlich-kaiserliche. Das hängt zum einen mit der besseren Quellenlage auf der Seite der Päpste zusammen zum anderen mit dem höheren Maß an institutioneller Festigung des Beraterkreises. Das Kardinalskollegium lässt sich im 11. und 12. Jahrhundert personell einfach besser greifen $^{55}$ als ein eher volatiler Beraterzirkel um die salischen Herrscher; zumal dieser Beraterzirkel angesichts einer ambulanten Herrschaftspraxis Fluktuationen ausgesetzt war und meist nur durch Urkundenausstellung deutlichere Konturen gewann. Für Heinrich IV. hat Alfred Gawlik den Bestand der Petenten und Intervenienten aus

zur Kaiser- und Papstgeschichte des Mittelalters. Beihefte zu J. F. Böhmer, Regesta Imperii 34) Wien 2013, 191-213.

51 Florian Hartmann, Kommunikation im Wandel. Medien, Autoren und Kontexte in den Debatten des Investiturstreits. Eine Einführung, in: ders. (Hrsg.), Brief und Kommunikation (wie Anm. 5), 9-21; ders., Kommunikation im Wandel. Ergebnisse, Ausblick und Desiderate, in: ebd., 381-391.

52 Tilmann Schmidt, Alexander II. und die römische Reformgruppe seiner Zeit. (Päpste und Papsttum 11) Stuttgart 1977.

53 Siehe oben Anm. 37.

54 Stefan Weinfurter, Reformidee und Königtum im spätsalischen Reich. Überlegungen zu einer Neubewertung Kaiser Heinrichs V., in: ders. (Hrsg.), Reformidee und Reformpolitik im spätsalischfrühstaufischen Reich. (Quellen und Abhandlungen zur Mittelrheinischen Kirchengeschichte 68) Mainz 1992, 1- 45.

55 Vgl. Claudia Zey, Entstehung und erste Konsolidierung. Das Kardinalskollegium zwischen 1049 und 1143, in: Jürgen Dendorfer / Ralf Lützelschwab (Hrsg.), Geschichte des Kardinalats im Mittelalter. (Päpste und Papsttum 39) Stuttgart 2011, 63-94; Jürgen Dendorfer / Ralf Lützelschwab (Hrsg.), Die Kardinäle des Mittelalters und der frühen Renaissance. (Millenio Medievale. Strumenti e Studi 95; N. S. 33) Florenz 2013; Ulrich Schludi, Die Entstehung des Kardinalkollegiums. Funktionen, Selbstverständnis, Entwicklungsstufen. (Mittelalter-Forschungen 45) Ostfildern 2014. 
den von ihm partiell edierten Diplomen herausdestilliert ${ }^{56}$, für Heinrich V. steht diese Arbeit noch aus, ist aber durch die elektronische Publikation der Diplomata inzwischen möglich ${ }^{57}$. Sicher würde man es nicht wie Gawlik vor über 40 Jahren bei der Auswertung der Urkunden bewenden lassen. Vielmehr würde man es heute mit dem methodischem Instrumentarium der Netzwerkforschung versuchen, sei es in der reinen Lehre der soziologischen „network analysis“, wie sie Robert Gramsch und andere betreiben $^{58}$, oder in einer weniger mathematischen Form mit anderen Bezeichnungen für Knoten, Cluster, Klein- und Großgruppen ${ }^{59}$. Der Reiz dieser Forschungen gerade auch bezogen auf unser Thema liegt in der offenen Herangehensweise: vom Zentrum zu den Ausläufern oder umgekehrt von regionalen zu überregionalen Verbindungen oder von Verwandtschaftsbeziehungen $\mathrm{zu}$ anderweitig institutionalisierten Kontakten. Vieles ist auf diesem Gebiet bereits geleistet worden, auch bezogen auf die hochmittelalterliche Papstkirche, ohne dass es unter dem Paradigma der Netzwerkforschung betrachtet worden wäre ${ }^{60}$.

Wenn ich die Publikationen zum Investiturstreit in den letzten Jahren richtig deute, liegt die Präferenz klar im regionalen Zugriff auf die Kreise der päpstlichen und

56 Alfred Gawlik, Intervenienten und Zeugen in den Diplomen Kaiser Heinrichs IV. (1056-1105). Der Übergang von der Interventions- zur Zeugenformel. (Münchener Historische Studien. Abt. Geschichtliche Hilfswissenschaften 7) Kallmünz 1970; DD H. IV.

57 Vgl. DD H. V., http://www.mgh.de/ddhv/toc.htm (Zugriff: 18.11.2018).

58 Vgl. Robert Gramsch, Autorität im Netzwerk der Fürsten. Friedrich II. und Heinrich (VII.) im Anerkennungswettstreit (1231-1235), in: Seibert/Bomm/Türck (Hrsg.), Autorität und Akzeptanz (wie Anm. 21), 43-64; ders., Das Reich als Netzwerk der Fürsten. Politische Strukturen unter dem Doppelkönigtum Friedrichs II. und Heinrichs (VII.) 1225-1235. (Mittelalter-Forschungen 40) Ostfildern 2013; Daniel Bauerfeld / Lukas Clemens (Hrsg.), Gesellschaftliche Umbrüche und religiöse Netzwerke. Analysen von der Antike bis zur Gegenwart. Bielefeld 2014.

59 Vgl. Eva Jullien, Netzwerkanalyse in der Mediävistik. Probleme und Perspektiven im Umgang mit mittelalterlichen Quellen, in: VSWG 100 (2013), 135-153; Kerstin Hitzbleck / Klara Hübner (Hrsg.), Grenzen des Netzwerks. 1200 -1660. Ostfildern 2014, bes. deren Einleitung, in: ebd., 7-15 sowie Kerstin Hitzbleck, Verflochten, vernetzt, verheddert? Überlegungen zu einem erfolgreichen Paradigma, in: ebd., 17-40; Marten Düring / Linda von Keyserlingk, Netzwerkanalyse in den Geschichtswissenschaften. Historische Netzwerkanalyse als Methode für die Erforschung von historischen Prozessen, in: Rainer Schützeichel / Stefan Jordan (Hrsg.), Prozesse, Formen, Dynamiken, Erklärungen. Wiesbaden 2015, 337-350.

60 Vgl. Gisela Drossbach / Hans-Joachim Schmidt (Hrsg.), Zentrum und Netzwerk. Kirchliche Kommunikationen und Raumstrukturen im Mittelalter. (Scrinium Friburgense. Veröffentlichungen des Mediävistischen Instituts der Universität Freiburg Schweiz 22) Berlin 2008; Jochen Johrendt / Harald Müller (Hrsg.), Römisches Zentrum und kirchliche Peripherie. Das universale Papsttum als Bezugspunkt der Kirchen von den Reformpäpsten bis zu Innozenz III. (Neue Abhandlungen der Akademie der Wissenschaften zu Göttingen 2) Berlin 2008; Jochen Johrendt (Hrsg.), Rom und die Regionen. Studien zur Homogenisierung der lateinischen Kirche im Hochmittelalter. (Abhandlungen der Akademie der Wissenschaften zu Göttingen N. F. 19) Berlin 2012; Klaus Herbers / Fernando López Alsina / Frank Engel (Hrsg.), Das begrenzte Papsttum. Spielräume päpstlichen Handelns. Legaten - delegierte Richter Grenzen. (Abhandlungen der Akademie der Wissenschaften zu Göttingen N. F. 25; Studien zu Papstgeschichte und Papsturkunden) Berlin 2013. 
königlichen Anhängerschaft ${ }^{61}$. Hier gibt es in der Tat noch etliche blinde Flecken, für die sich eine Untersuchung der Gruppenbindungen in überschaubarem Umfang lohnt ${ }^{62}$. Aber auch in größerer Dimension sollte man diese Herangehensweise erwägen, da sie mit Sicherheit zu neuen Einsichten in die Kräfteverhältnisse führt.

Päpstliche Legaten etwa würden sich durchaus für eine Analyse ihrer weitgespannten Beziehungen eignen, wenn sie ein bestimmtes Legationsgebiet länger frequentierten und nachweislich mit einer größeren Anzahl von Personen in Beziehung traten $^{63}$. Die Quellenlage schränkt den Kreis der in Frage kommenden Legaten für eine ego-zentrierte Netzwerkuntersuchung ${ }^{64}$ zwar ein, aber einige prominentere Kardinäle kommen in Betracht. Denken wir nur an den Kardinalbischof Kuno von Praeneste oder Palestrina, einen Deutschen im Kardinalskollegium Papst Paschalis' II., der in der Zeit von 1116 bis 1120 in mehreren Legationen von Frankreich aus die Opposition gegen

61 Beispielhaft seien genannt: Jean-Hervé Foulon, Église et réforme au Moyen Âge. Papauté, milieux réformateurs et ecclésiologie dans les Pays de la Loire au tournant des $\mathrm{XI}^{\mathrm{e}}-\mathrm{XII}{ }^{\mathrm{e}}$ siècles. (Bibliothèque du Moyen Âge 27) Brüssel 2008; Florian Lamke, Cluniacenser am Oberrhein. Konfliktlösungen und adlige Gruppenbildung in der Zeit des Investiturstreits. (Forschungen zur oberrheinischen Landesgeschichte 54) Freiburg 2009; Jürgen Dendorfer, Regensburg im „Investiturstreit“. Prüfenings Anfänge im Kontext der Stifts- und Klostergründungen um 1100, in: Arbeitskreis Regensburger Herbstsymposion (Hrsg.), 900 Jahre Prüfening. Kloster - Schloss - Schule. Beiträge des 24. Regensburger Herbstsymposions für Kunst, Geschichte und Denkmalpflege vom 13. bis 15. November 2009. Regenstauf 2010, 17-27; Eva Schlotheuber, Diruit, aedificat, mutat quadrata in rotundis. Die Würdigung der Eichstätter Bischöfe in den schwierigen Zeiten des Investiturstreits, in: Johannes Gießauf / Rainer Murauer / Martin P. Schennach (Hrsg.), Päpste, Privilegien, Provinzen. Beiträge zur Kirchen-, Rechts- und Landesgeschichte. Festschrift für Werner Maleczek zum 65. Geburtstag. (MIÖG. Ergänzungsbd. 55) Wien 2010, 377-391; Tobie Walther, Zwischen Polemik, Verschweigen und pragmatischem Umgang. Der gregorianische Gelehrtenkreis um Bernold von Konstanz und die Straßburger Bischöfe im Investiturstreit, in: Laurence Buchholzer-Rémy / Sabine von Heusinger / Sigrid Hirbodian (Hrsg.), Neue Forschungen zur elsässischen Geschichte im Mittelalter. (Forschungen zur oberrheinischen Landesgeschichte 56) Freiburg 2012, 53-71; Stefan Weinfurter, Verantwortung und Politik. Der Mainzer Erzbischof und seine Stadt im Investiturstreit, in: Anna Esposito u. a. (Hrsg.), Trier - Mainz - Rom. Stationen, Wirkungsfelder, Netzwerke. Festschrift für Michael Matheus zum 60. Geburtstag. Regensburg 2013, 89-108; Tobie Walther, Zwischen Polemik und Rekonziliation. Die Bischöfe von Straßburg im Investiturstreit bis 1100 und ihre Gegner. (Veröffentlichungen der Kommission für geschichtliche Landeskunde in Baden-Württemberg. Reihe B. Forschungen 210) Stuttgart 2017.

62 In diesem Sinne untersucht Johannes Luther (Zürich), Die Vernetzung burgundischer Bischöfe (1032-1156) ‘ (Arbeitstitel) im Rahmen seines Dissertationsprojekts.

63 Zum Forschungsstand vgl. Claudia Zey, Stand und Perspektiven der Erforschung des päpstlichen Legatenwesens im Hochmittelalter, in: Johrendt (Hrsg.), Rom und die Regionen (wie Anm. 60), 157166; auf Italienisch: dies., Legati papali e delegati papali (secoli XII-XIII). Stato della ricerca e questioni aperte, in: dies. / Maria Pia Alberzoni (Hrsg.), Legati e delegati papali nei secoli XII e XIII. (Vita e Pensiero.) Mailand 2012, 3-12; Harald Müller, The Omnipresent Pope. Legates and Judges Delegate, in: Keith David Sisson / Atria A. Larson (Hrsg.), A Companion to the Medieval Papacy. Growth of an Ideology and Institution. (Brill's Companions to the Christian Tradition 70) Leiden / Boston 2016, 199 219.

$64 \mathrm{Zu}$ ego-zentrierten oder Ego-Netzwerken vgl. Dorothea Jansen, Einführung in die Netzwerkanalyse. Grundlagen, Methoden, Forschungsbeispiele. Wiesbaden ${ }^{32006,} 65$ und 79 f. 
Heinrich V. fast im Alleingang organisierte und schon in der Krise von 1111 als kompromissloser Gegner des Saliers hervortrat ${ }^{65}$. Von ihm sind 24 Urkunden überliefert und auch historiographisch ist er gut bezeugt ${ }^{66}$. Seine Kontaktpersonen sind zwar grosso modo bekannt, aber eine Feinanalyse seiner Beziehungen verspricht tiefere Einsichten in die Kommunikationsmuster der Kaisergegner ${ }^{67}$.

Damit ist diese Tour d'horizon über neuere Forschungsansätze zur Schriftproduktion, deren Interpretation und zur persönlichen Vernetzung bereits bei den Desiderata in der Erforschung des Investiturstreits angekommen.

Ganz generell ist die Zeit von 1046 beziehungsweise von 1073 bis 1099 besser durchdrungen als diejenige nach 1100. Das mag auch daran liegen, dass Gregor VII. und Urban II. schillerndere Gestalten auf dem Papstthron waren als Paschalis II. und dass die Regierungszeit Heinrichs V. durch die fehlende Diplomata-Edition und damit einhergehend durch die fehlende Aufarbeitung in den Regesta Imperii weniger gut erforscht ist. An einem ruhigeren Verlauf des Konflikts nach 1100 kann es aber nicht liegen. Das wiederholte Scheitern einer Einigung zwischen regnum und sacerdotium in den Jahren 1105/06, 1111 und 1119 wirkte einschneidend auf Kirche, Reich und Regionen und manifestierte Spaltungen und Schismen langfristig. Die Folgen der Konflikte dauerten bis weit über das formale Ende des Streits 1122/23 hinaus an. Es erscheint daher sehr sinnvoll, die Neugier einstweilen eher auf die Zeit um 1100 und die nachfolgenden Jahrzehnte zu lenken als immer wieder auf die frühe Phase (mit und ohne Canossa) ${ }^{68}$.

Wenn Leidulf Melve anhand der Streitschriften konstatiert, dass die Zeit zwischen 1099 und 1122 durch weniger auf öffentliche Wirksamkeit gerichtete Debatten gekennzeichnet gewesen sei, entspricht das der weit verbreiteten Ansicht von der Hochphase des Konflikts bis 1099 und ihren intellektuellen Ausläufern nach 1100, in denen die Lösung des eigentlichen Investiturproblems mit der Trennung von spiritualia und temporalia zur Reife gelangte. Wenn wir aber nur die eben evozierten Ereignisse Revue passieren lassen (die Absetzung Heinrichs IV. durch seinen Sohn in Ingelheim 1105, das Scheitern der Aussöhnung zwischen Paschalis II. und Heinrich V.

65 Vgl. Rudolf Hiestand, Legat, Kaiser und Basileus. Bischof Kuno von Praeneste und die Krise des Papsttums von 1111/1112, in: Horst Fuhrmann / Hans Eberhard Mayer / Klaus Wriedt (Hrsg.), Aus Reichsgeschichte und Nordischer Geschichte. Festschrift für Karl Jordan zum 65. Geburtstag. (Kieler Historische Studien 16) Stuttgart 1972, 141-152.

66 Vgl. Stefan Weiß, Die Urkunden der päpstlichen Legaten von Leo IX. bis Coelestin III. (1049-1198). (Forschungen zur Kaiser- und Papstgeschichte des Mittelalters. Beihefte zu J. F. Böhmer, Regesta Imperii 13) Köln 1995, 61-70.

67 Beispielhaft für die Untersuchung eines solche Ego-Netzwerkes ist eine neuere Untersuchung zu den Beziehungen Abt Odos von Cluny: Isabelle Rosé, Reconstitution, représentation graphique et analyse des réseaux de pouvoir au haut Moyen Âge. Approche des pratique sociales de l'aristocratie à partir de l'exemple d'Odon de Cluny (†942), in: REDES. Revista hispana para el análisis de redes sociale 21 (2011), 199-272.

68 In meiner Gesamtdarstellung des Investiturstreits habe ich daher großen Wert auf die Darlegung der Zusammenhänge für die Zeit nach 1100 gelegt, vgl. Zey, Investiturstreit (wie Anm. 6), 85-112. 
1106, die erzwungene Kaiserkrönung des Saliers nach der Gefangennahme von Papst und Kardinälen in Rom 1111, das erneute Scheitern einer Einigung in der Investiturfrage samt einem geplatzten Treffen zwischen Heinrich V. und Calixt II. 1119 in Mouzon), dann waren das hochbrisante Vorgänge, die sich vor einer großen Öffentlichkeit in Deutschland, Italien und Burgund abspielten. Wenn man dann noch bedenkt, wie es den päpstlichen Stellvertretern, nicht nur dem schon erwähnten Kardinal Kuno, gelang, gegen den salischen Herrscher auf großen Synoden und königlosen Hoftagen $\mathrm{zu}$ agieren, dann geben die Streitschriften dieser Zeit anscheinend nur noch ungenügend Auskunft über die öffentlich geführten Debatten. Hier gilt es meines Erachtens anzusetzen, wenn man den Investiturstreit als Erklärungsmodell für die umfassenden Veränderungen im hochmittelalterlichen Europa namhaft machen will. 
